\title{
Vortex Furnace or Vortex Mixer in Life Furnaces
}

\author{
Svetlana Zakharchenko, Nikolay Zakharchenko, Sabina \\ Nedbailik, Ernest Tsypkin \\ Petrozavodsk State University, Petrozavodsk, Russia \\ zco59@mail.ru, snedbailik@mail.ru, france@petrsu.ru
}

\begin{abstract}
The present article concerns main functional features, working principles, technical device advantages of the vortex mixer named Maxwell's demon after the genial American physicist J.C. Maxwell. On the base of a multi-aspect study experimental data and results the authors state considerable technical and economic effects of the vortex furnaces every-day life and wide-scale industrial use. Numerous schemes and figures presented in the article help to get an adequate idea of the invention in question.
\end{abstract}

Key-words: door keeper, device, vessel, process, heating energy, experiment, vortex furnace, mixer, outlet

\section{INTRODUCTION}

This idea has been proposed to the world by a genial physicist James Clerk Maxwell. Supposing that there are two vessels with room air, connected to each other by a wall, which has got a door- lock. As it can be seen in fig.1, both vessels have quick (hot) molecules and less quick cold molecules - all is, as it has been proved by Maxwell's distribution. Let us suppose that there is a guard, door-keeper standing by the door-lock (a green circle in the center). This guard- door keeper lets -in into one selected vessel (say, right vessel on the drawing) only quick molecules (red dots on the right), and lets out back only slow molecules (blue dots on the left). The longer this door keeper is working, the more hot molecules will be in the right vessel and cold ones in the left vessel. The process will cause the heating of one vessel and cooling of the other. The scientists have named this guard - door keeper Maxwell's demon and proved by the way the impossibility of its self-sufficient existence basing on the postulate of thermodynamics second law. This postulate claims that entropy (chaos) measure can only grow (be above zero) in a closed reserved system. 


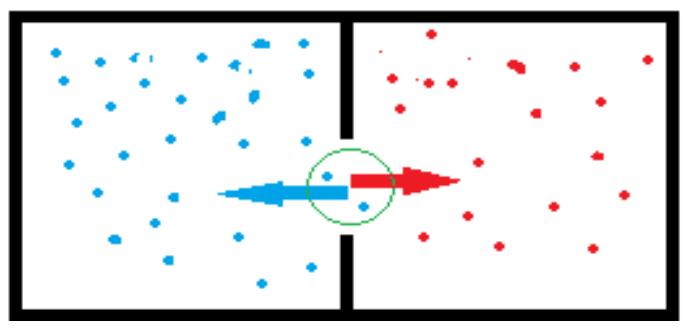

Fig. 1: The illustration of a mental experiment; Maxwell's demon

\section{Ranque-Hilsh Tube, Vortex Effect}

Later, the engineer J. Ranque appeared in 1931 with an unusual device, being a small tube, into which the air was fed tangentially through a nozzle. Ranque`s device had two issues in the opposite ends of the tube, so the cold air went out from one side and the hot air - from the other side. In this case Ranque`s tube, de facto, was doing Maxwell demon`s work, because in it the room air was separated while its feeding into two flows of different temperature [Patent 74311 - France]. And this seemed then, at the first consideration, a phenomenon contradicting the second law of thermodynamics. Ranque and his tube were forgotten just after his report made at the French physical society, what seems even more unusual that Ranque`s device itself. Probably, a fixed stereotype effect has told upon in the situation: all that is new, that contradicts the science postulates is usually declared anti-scientific, and adepts of this new are ranked among sectarians - obscurants, hindering humanity movement towards progressive future. In such conditions not every scientist can find inner forces to defend his point of view. Only 15 years later, in 1946, the physicist R. Hilsh rediscovered the vortex effect and could explain in a language of formulas the work of this device, which is known today as Ranque-Hilsh tube (see fig.2), or vortex refrigerator, vortex energy separator or, more often, vortex tube [6], [7].

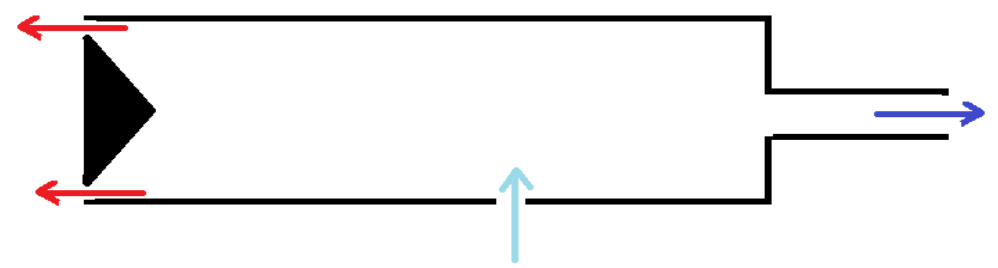

Fig. 2. The diagram of Ranque - Hilsh tube. Blue arrow - air tangential feed. Dark blue arrow cold air outlet; red arrow - hot air outlet.

The difference of temperatures at the outlet between two ends of modern Ranque`s tube can reach $80^{\circ}$ in room temperature conditions and depends on air feed rate, as well as on the tube geometry. Very soon an experimental fact has been stated: inside Ranque tube the air behaves not like a quasi-solid body, as it was supposed initially (see fig.3). In Ranque`s tube the flow is divided into two layers, rotating in different directions. The layer on the outside rotates in the direction, where the air - primary source is guided. The layer by the center rotates in the opposite direction. 


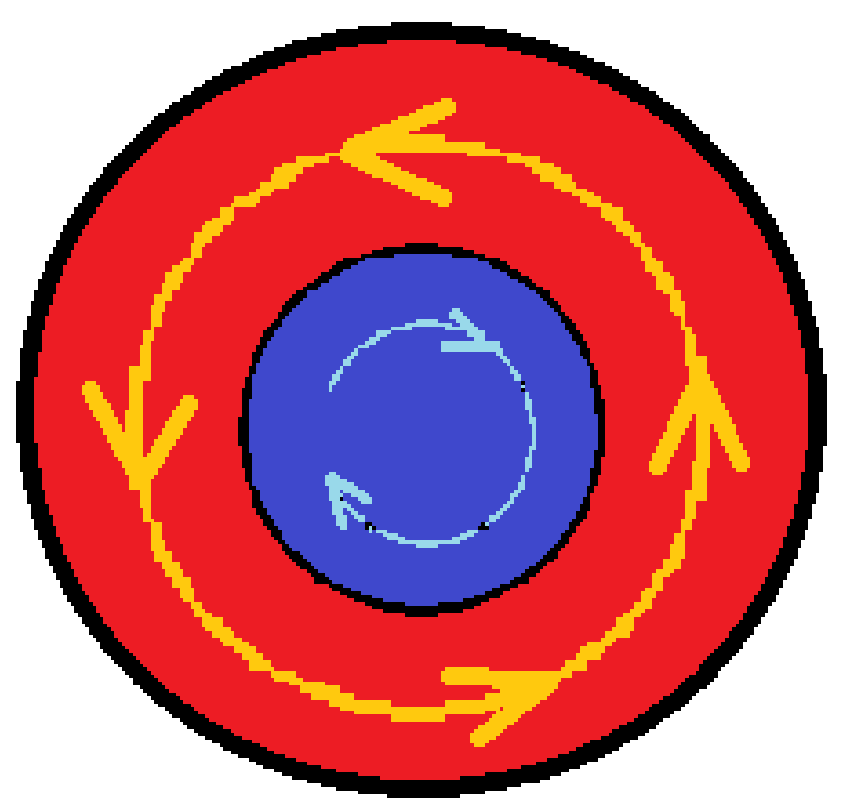

Fig. 3. Flow stratification inside Ranque-Hilsh tube

- How can it be possible?

It seems to me that a mental experiment will be quite proper in this case. Let us draw the sectional view of the vortex tube (see fig.4).

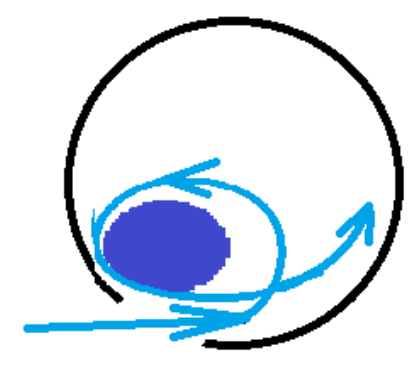

Fig. 4. The diagram of one vortex forming.

One feeds air by the direction of the blue arrow. Then in the place, where a blue circle is drawn, we will have a zone of lower pressure. Towards this zone will deviate the flow - a vortex will appear. If we unite the vortices into a whole cycle, the picture will be as on the drawing of German genial scientist Victor Schauberger for the water vortex (see fig. 5). We have marked by a blue arrow the air-source feed. It is seen in the drawing, how the vortex, running by the contour of the tube, reinforces rotation in the outer layer and whirls the flow in the center in the opposite direction [8]. 


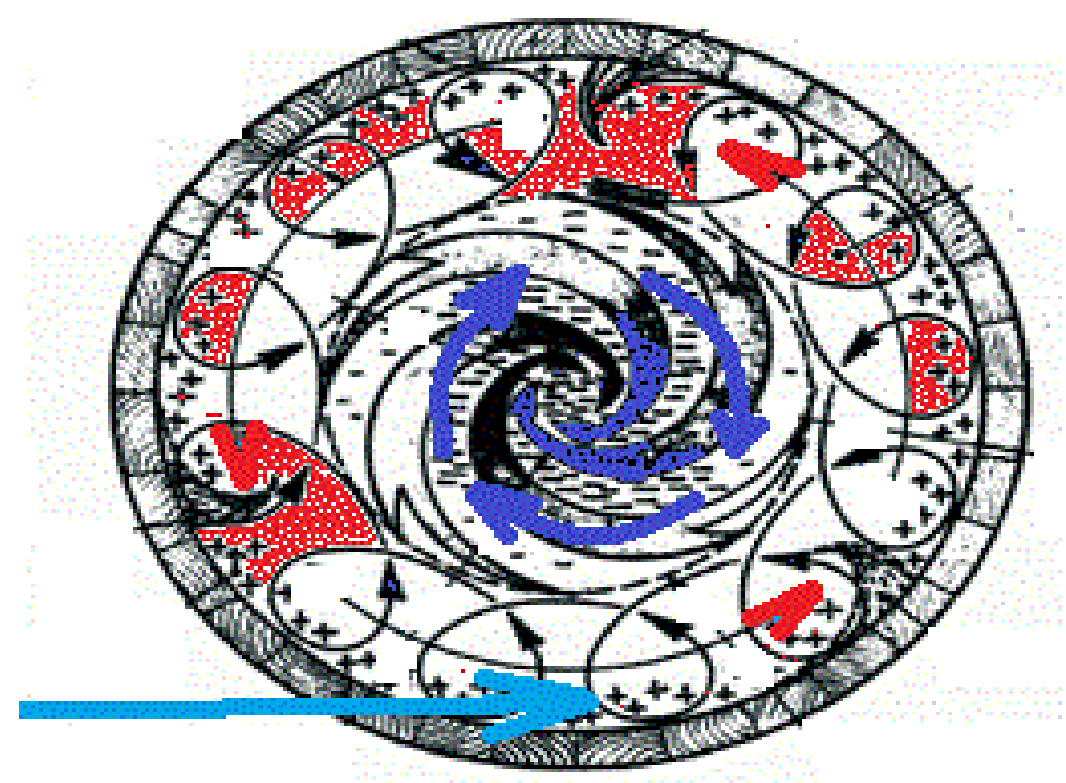

Fig. 5. Schauberg`s illustration with color supplements

There is an assumption, that an analogous scheme exists in the natural phenomenon of tornado [9], [10].

\section{Theoretical and Practical Grounds}

It is interesting for us to create in the furnace fuel cell such conditions, that would lead to burning products best combustion and promote optimal medium for burning. The academician N. N. Semenov created in 1926-1927 the heat theory of gas fuels self-ignition. Under temperatures lower than the temperature of combustion a low-rate chemical reaction takes place in a gas, and the heat - dissipation through the wall balances reaction heat income into outer environment. The reaction rate grows with the temperature increase, and conditions are created when the heat-dissipation is no longer able to balance the heat income and the heat avalanche is produced. N.N. Semenov has shown, that the burning reaction is a chain reaction, and has got a Nobel prize for this theory development [4]. The heat avalanche presents the burning flame front, and it was shown in the work [1] that in case of flame spreading the burning reaction takes place in every time moment in a comparatively thin layer (in comparison with the fuel cell dimensions), and two parameters influence especially this process: pressure and temperature. Y.B. Zeldovitch has discovered on the example of hydrogen and oxygen reaction three limits of ignition, which he has illustrated in the form of a diagram «pressure - temperature» [1]. If the mixture primary pressure and temperature values correspond to the dot lying to the right of the curve $\mathrm{ABCD}$, the ignition takes place; the section $\mathrm{AB}$ corresponds to the first, the section $\mathrm{BC}$ - to the second and the section $\mathrm{CD}$ - to the third limit of selfignition. The field between the first and second limits is called «the ignition peninsula». For the house-hold furnaces, working under pressures, close to the atmospheric one, is most interesting the third limit of ignition. In this zone we can see 
Gyancity Journal of Electronics and Computer Science,

Vol.4, No.2, pp. 1-14, September 2019

ISSN: 2446-2918 DOI: 10.21058/gjecs.2019.42001

almost linear decrease of ignition temperature in case of pressure increase (see fig.6). And proceeding from the fact that ignition takes place in the thin layer, and not in the volume, we can obtain better ignition by means of non-uniformities of pressure appearance in the working mixture, i.e. by means of turbulence zones creating in it. Then inside the zone the pressure can be decreased, and on the surface of this zone increased, just where the process of ignition will develop. This fact is approved by the work [3], where is shown, that a sufficiently quick burning, in case of which the flame moving speed value reaches hundreds of $\mathrm{m} / \mathrm{sec}$., takes place with gas mixture vortex generating and, correspondingly, with flame front turbulization. This turbulization causes the flame front considerable spreading, the heat exchange between burning products and initial mixture and, correspondingly, burning process acceleration [3].

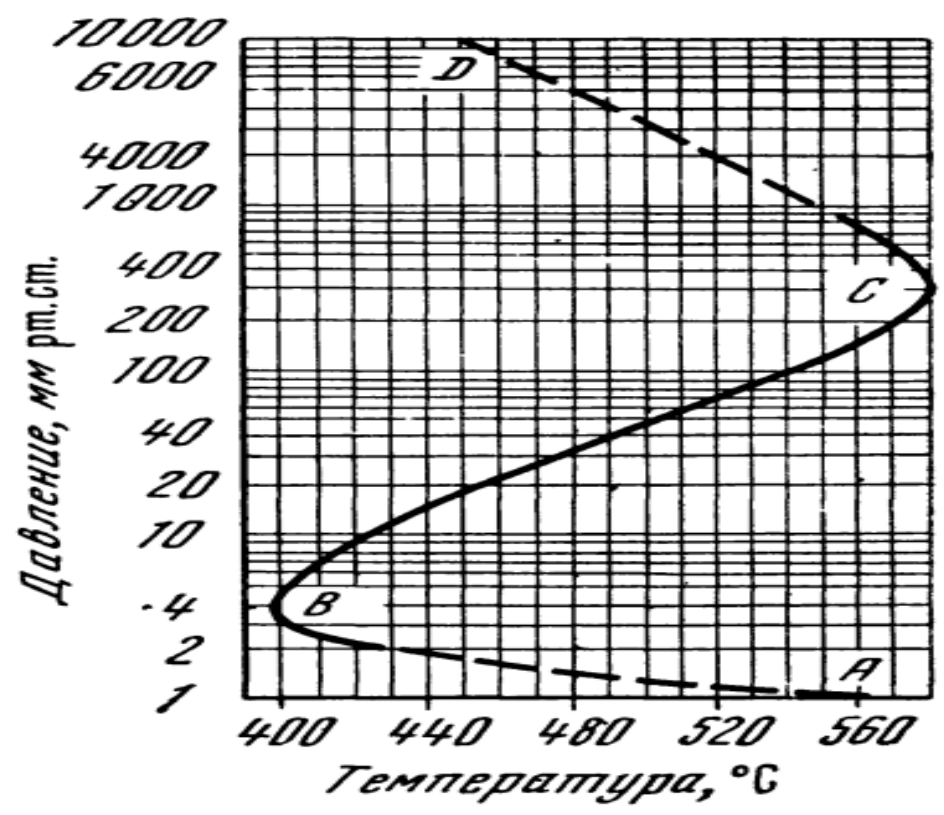

Fig. 6. The diagram of hydrogen and oxygen stacheometric mixture ignition range.

Some plants have already used burning products turbulization in practice, for example, the academician M. A. Styrikovitch [2] has described such plants for coal burning (see fig.7). 
ISSN: 2446-2918 DOI: $10.21058 /$ gjecs.2019.42001
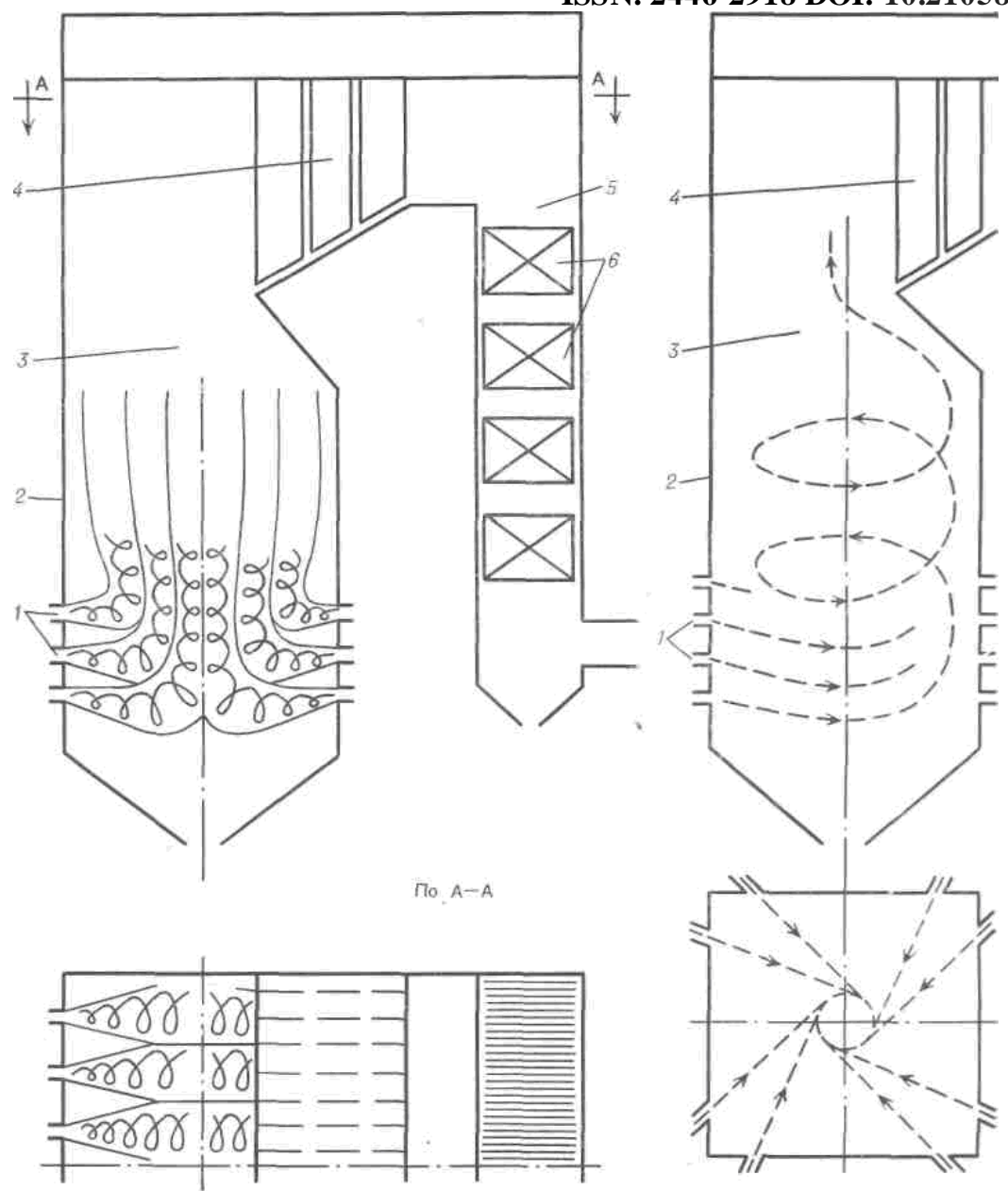

Рнс. 1. Схема труппого котлоагрегата и тонотного устройетва со встречным многоярусшым расположением вихревых горелок

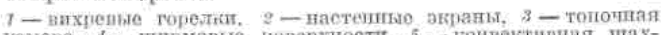
камера, 4 - ширмовыс поверхности, 5 - конвентиния шахтан, 6 - коннективные поверхності натрена

Prс. 2. Cxema круmшого ко:лоатрегата II тошочного устройтва с тантептиальными мнотояруснымі пеле вымп горедкамп

1- целенье горелки, 2- на1 - целеные горелки, $2-$ накамера, 1 - ширмопые поперхності

Fig. 7 M.A. Styrikovitch`s plants view

The air and coal dust flows are fed into the furnace in a swirled condition. The tangential disposition of burners by the furnace angles creates in it a general swirling vortex. Here not only each individual burner causes a vortex flow, but also all the totality of burners creates a united vortex [2]. Not ordinarily is used the vortex effect in vortex radiators (compression waves generators), what are widely applied in oil fields (see fig.8). Outwardly the generator resembles Ranque' tube, but unlike this tube it hasn 't got a back outlet, and the direct outlet is opened. When the fluid is fed through a tangential hole 2 of diameter $d$ inside the chamber of vortex 3 and outlet nozzle 4 of the generator is formed the system of two swirling flows (see fig.8). By the chamber periphery is moving a so called primary vortex. The vortex chamber axial surface is filled by the secondary vortex. The experience shows that in case of fluid jet non-flooded discharge (for example, when it is discharged into gaseous 
medium) moving is stable, pressure and velocity fluctuations are not present in the flow.

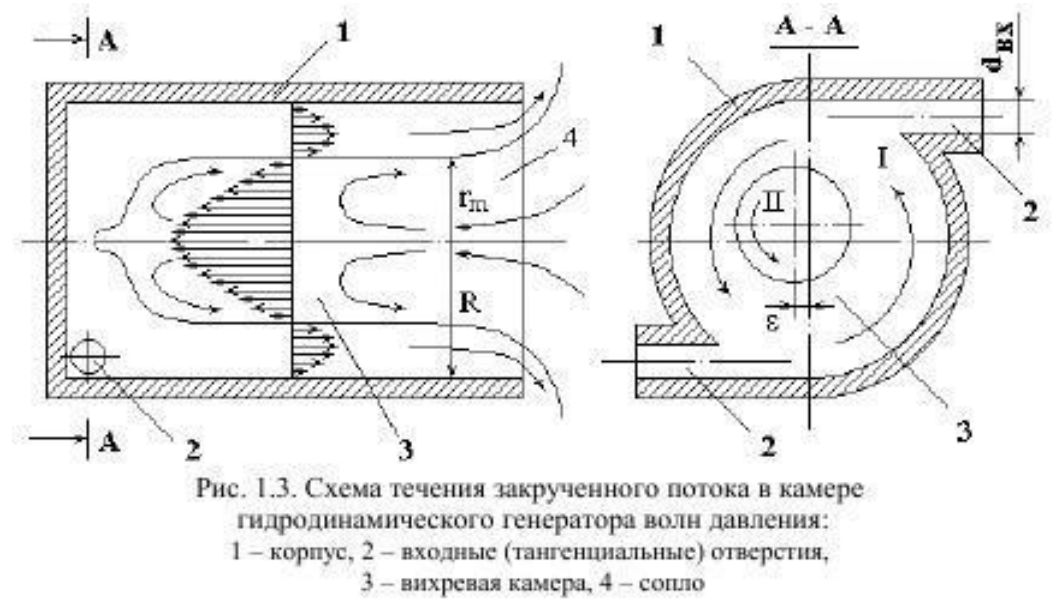

Fig. 8 Compression waves generating

If the swirling jet discharge is flooded, i.e. the working mixture in the vortex chamber and the environment substance have the same physical nature, then in the flow are generated regular pressure fluctuations, the frequency and amplitude of which depend on discharge rate and geometric parameters of vortex chamber, its design and the nozzle form. In the environment the pressure fluctuations are fixed as the sound of discrete tone and high intensity [5]. In other words, the device starts uttering harsh sounds, when it is found in the environment of density, similar to the density of working fluid - it recognizes its own similitude.

\section{Vortex Mixer (VM)}

Vortex mixers in house-hold furnaces are analogous to Ranque' tubes and their derivatives (see fig.9). We started making the first furnaces with such VM in 2011, and We are making them till present. What does it give?

1. Its gives burning products mixing in the fuel cell. What is mixing needed for? We will try to illustrate it on the ordinary life level. Let's take 10 tea spoons of sugar and pour them into a glass of warm water without mixing. The sugar will be hardly felt on taste despite its abundance, since it will remain on the bottom of a glass. Still, the practical experience prompts, that one teaspoon of sugar is quite enough to make the tea sweet, if we only mix the liquid with a teaspoon. What has mixing given us?... $\mathrm{VM}$ is just such a spoon for mixing burning products in a fuel cell. Only this reason is already quite valid to supply a VM to every fuel cell. VM mixes pyrolysis gases with the air oxygen, thanks to what the burning reaction is much more intensive and takes place with less consumption of air oxygen. In fact, the air can be fed in the furnace with VM almost in stacheometric amount: for $1 \mathrm{~kg}$ of fuel - about 6-8 $\mathrm{m} 3$ (alpha1-1.25), at the same time, today in the furnace world this figure is admitted as 10-12 $\mathrm{m} 3$ (alpha about 1.7-2). As a result, in the furnace there is less parasitic air, not 
ISSN: 2446-2918 DOI: 10.21058/gjecs.2019.42001

involved in burning process. In other words, it is just the air that passes through the furnace as transit and carries out the heat. Some pleasant moments can be found in a fuller burning reaction and in fuel consuming reduction. Also, are reduced the harmful blow-out into the environment and carbon-black formation on the furnace walls. As far as parasitic air consuming is reduced, gas mixture temperature grows, what increases exponentially the burning reaction rate according to the formula of Arrenius. And, also, according to Semenov` postulate [4]: «With temperature growing the reaction rate increases and conditions are created, when heat-dissipation doesn't manage to compensate heat income and heat avalanche is produced». 2. Vortex mixing in a fuel cell produces local zones with pressure difference or compression waves [5], what, in accordance with [1], can lead jump - likely to ignition even under lower temperature.

3. Vortex mixing in a fuel cell creates turbulence in the gas mixture, what, according to Styrikovitch [2], causes flame front considerable spreading, heat exchange between burning products and initial mixture and, correspondingly, burning acceleration. 4. Vortex mixing in a fuel cell separates the burning flow by the temperature, picking up the hot burning front on a wall, where the main heat exchange processes are taking place, and dropping down the cold burning front on the center, thus localizing their effect up to a minimum.

\section{Embodiment}

Till present VM has been tested in a fuel cell of a rectangular, square and pentagon form with vortex slots by the edges. For most classical form furnaces it looks as. Just this VM sample is used by me in practice at present, but vortex slots are usually left only in corners for small fuel cells, 2-3 nozzles being quite sufficient for this. The air is fed for burning through an inter-lining slot (blue pencil). These slots are tightly jammed by a not tough thermal insulator, not to let air into convection system (green pencil). Vortex approaches are made in this case on the right and on the left on the drawing. Below (by the drawing) we have got an opening for the feed door, above there is a convection system channel on the drawing. Each vortex channel laying brick is undercut for $45-60^{\circ}$, forming a nozzle - slot in a narrow place 10-15 $\mathrm{mm}$, through which air is let into the fuel cell. follows. Such a way of air feed causes decreased pressure behind the flow, what, in its turn, leads to the flow whirling with vortex forming (black arrows). The air total traffic by the furnace chamber will remind a cycloid moving with macro-rotation (as it is shown by red arrows). In principle, one can arrange a vortex mixer through any nozzles number and with any combination of sides. Moreover, this can be accomplished with furnaces of any geometry (triangular, pentagon, $\mathrm{N}$-angular). In this case, «the hearth» (i.e. the lower 
base) of fuel cell can be «blind» (i.e. solid), can be combined with a fire bar.
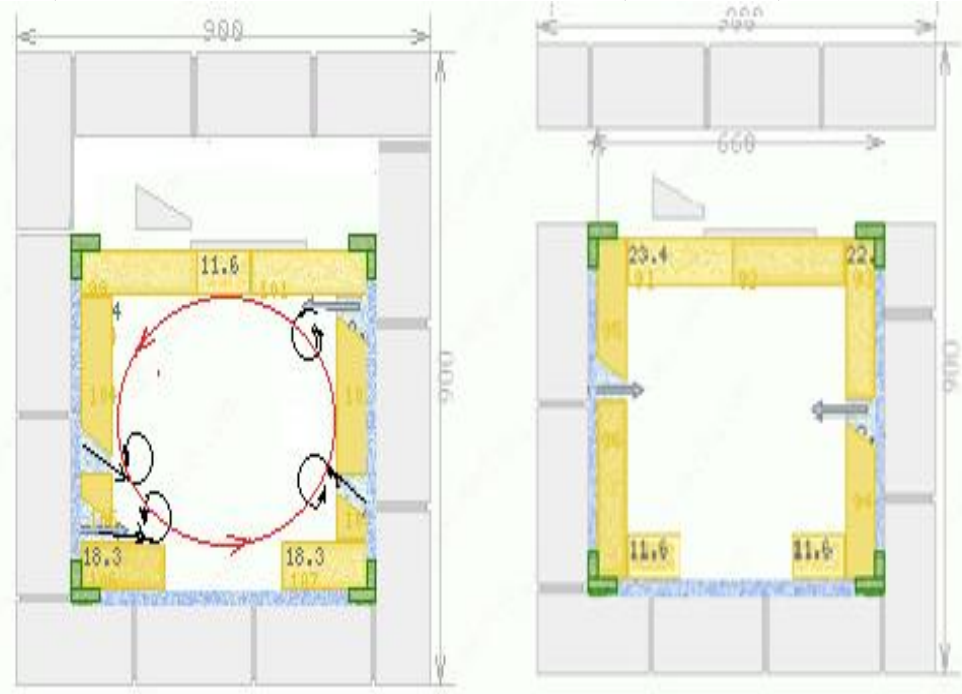

Fig. 9. VM in a house-hold furnace -the section in the area of furnace door, view from the top

As it is seen in fig.10, air feed in this case is possible either from outside, or from the room. The air that is let into the fuel cell is previously heated in the inter-lining space. Also, VM is applied in the convection system (CS) and in the afterburning chamber (ABC), as well as in the chimney stack device.

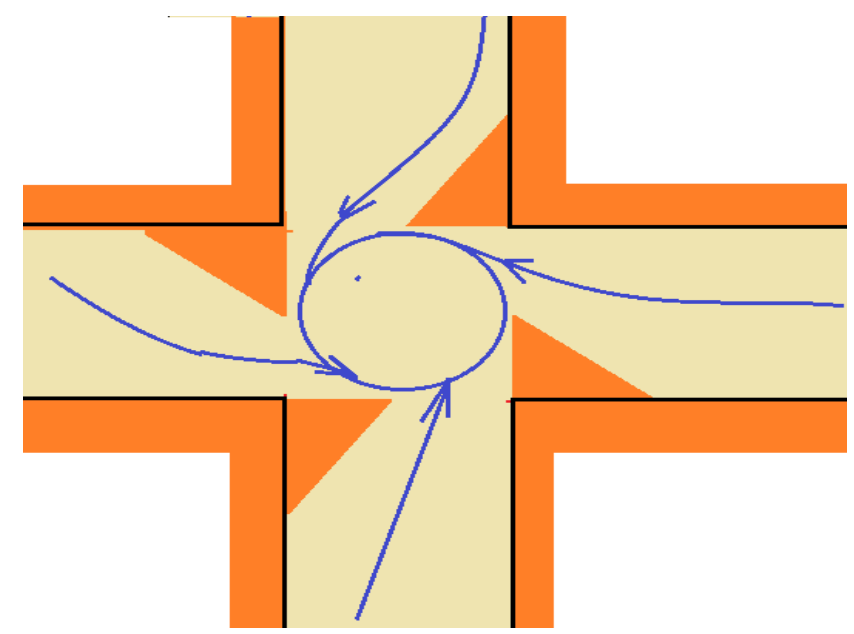

Fig. 10. Intersections isolation for the case of four oncoming flows. View in the plan, tube in the center.

In VM it is not the same in what direction is vortex whirled - this is to be considered in designing nozzles vortex slots. It is important that gas mixture ways through a fuel cell, after-burning chamber, convection system and chimney stack wouldn't have selfintersections and fractures. And also, to prevent possible conflicts of opposite 
direction motion vortices, it is admitted to use only one (right or left, but not both together) direction of gas flow whirling in different parts of one furnace plant.

\section{Vortex Mixer (VM)}

Vortex mixer (VM) can be used for heat energy producing from carbon containing compounds burning and after-burning (such types of fuel as firewood, pit coal, hydrogenous coal, coal dust, wood chips, saw-dust, peat, gas, oil, etc.) with low noxious substances blow-out into the environment; the invention is applicable in industry, for example, in process and district heating systems introduction chains, as well as in house-hold conditions, in particular, in ordinary room furnaces. The problem, being solved by the invention, is creating optimal conditions for chemical combustion reaction, ballast gases separation, working mixture chemical interaction time prolongation, working mixture temperature increase and carbon containing substances harmful blow-out decrease. This problem can be solved, since VM device (see fig.11,12,13) is characterized by a mixing chamber $(1,2,3,12,20,28)$, consisting of three vertical $(1,2,3)$ units, with a round, triangular, square, pentagon, hexagon or any $\mathrm{N}$-angle form section, where $\mathrm{N}$ - any whole number $>2$, arranged one above another; to the first (1) unit (see fig.12) are supplied symmetrically disposed vortex channels (for example, $7,8,9,10,11$ ) in a quantity of not less than one channel, for air feed into the mixing chamber, to the second (2) unit (see fig.13) are supplied symmetrically disposed vortex channels (for example: 15, 16, 17, 18, 19) in a quantity not less than one channel, for feeding carbon containing gases or gas dust into the mixing chamber; in this case each of vortex channels (for example: 7, 8, 9, $10,11$ и $15,16,17,18,19)$ presents a passage, narrowing towards the mixing chamber $(1,2,3,12,20,28)$ and directed along the mixing chamber wall in one strictly chosen side (either only clockwise, or only counter - clockwise), and, consequently, causes vortex flows along the mixing chamber wall in given direction of cycloid form around the mixing chamber central vertical axis; from the third (3) unit (see fig.14) extends an uncurling device (4), presenting branched channels for hot gases, oriented along the mixing chamber wall, but in a direction opposite to the direction of first and second units channels; contains in the third (3) unit (see fig.14) a diaphragm (5) for cold gases drop, presenting a mixer cover with a hole in the radius center. The technical result, provided by the given features totality, is the working mixture mixing in a vertical and horizontal directions, what lets passing the burning reaction with a minimal quantity of ballast air; natural separating of having reacted, hot gases from cold gases, not involved in burning, with a possibility of hot gases further using in heat engineering purposes; the working mixture burning with its rotation by cycloid prolongs these gases interaction way with a fixed rate under influence of the tube natural draught (or artificial draught, if it is used) for the value $\mathrm{L}=2 * \mathrm{pi}^{*} \mathrm{R} * \mathrm{~N}$; where pi $=3.149265$ is $\mathrm{Pi}$ number, $\mathrm{R}-$ burning cycloid mixer radius, $\mathrm{N}$ - the number of rotations, which will be made by the working mixture along the mixer wall; the working mixture is held in the mixer zone longer for the value $t=L / v$, where $\mathrm{v}$ - gases linear speed under the influence of the tube natural draught (or artificial draught, if it is used), what leads to the chemical interaction time prolongation and increases the percent of reacted gases; the working mixture 
detention in the mixer zone leads to the temperature increase in VM, and, subsequently, carbon containing gases involving in burning reaction with a higher temperature of chemical interaction, thus plant capacity and burning integral efficiency are growing.

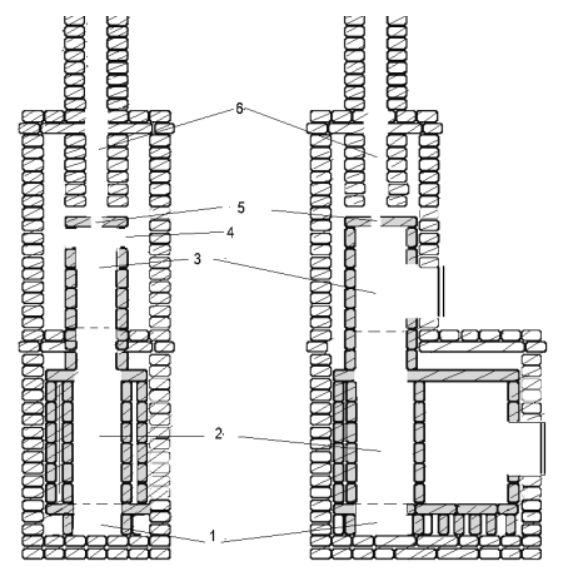

Fig. 11. On the drawing above - VM in a house-hold furnace compound - vertical sections. Symbols: 1 - first section of pentahedron VM , 2 - second section of pentahedron VM, 3 - third section of pentahedron VM, 4 - uncurling device, 5- diaphragm, 6 - tube

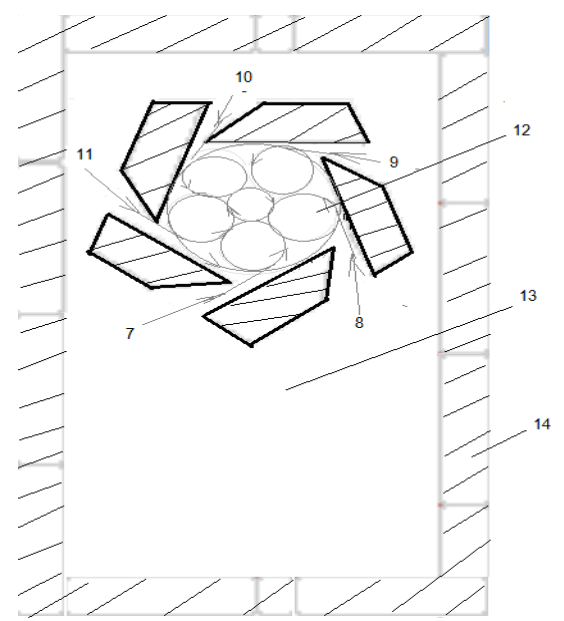

Fig. 12. VM in a house-hold furnace compound - section in the plan, first (1) unit. The arrows show the air traffic direction. Five big vortices create external macro-motion in the secondary air feed direction, inside is formed a vortex pole, rotating in a direction opposite to external macro motion. Symbols: 7, 8, 9, 10,11 - channels for air feed into the mixing chamber; 12 - VM first (1) unit, 13 -air preliminary heating chamber, 14 - air preliminary heating chamber partition. 
ISSN: 2446-2918 DOI: 10.21058/gjecs.2019.42001

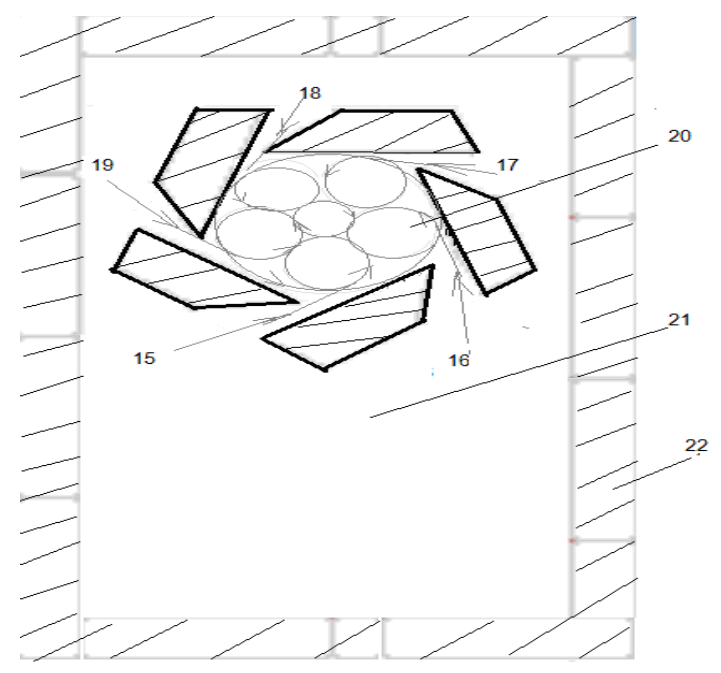

Fig. 13. VM in a house-hold furnace compound - section in the plan second (2) unit. The arrows show the working mixture motion direction. Five big vortices create external macro-motion in fuel mixture feed direction, inside is formed a vortex pole, rotating in direction opposite to external macro-motion. Symbols: 15, 16, 17, 18, 19 - channels for feeding carbon containing gases or coal dust into the mixing chamber; 20 - VM second (2) unit, 21 -primary burning chamber, 22-primary burning inner chambers.

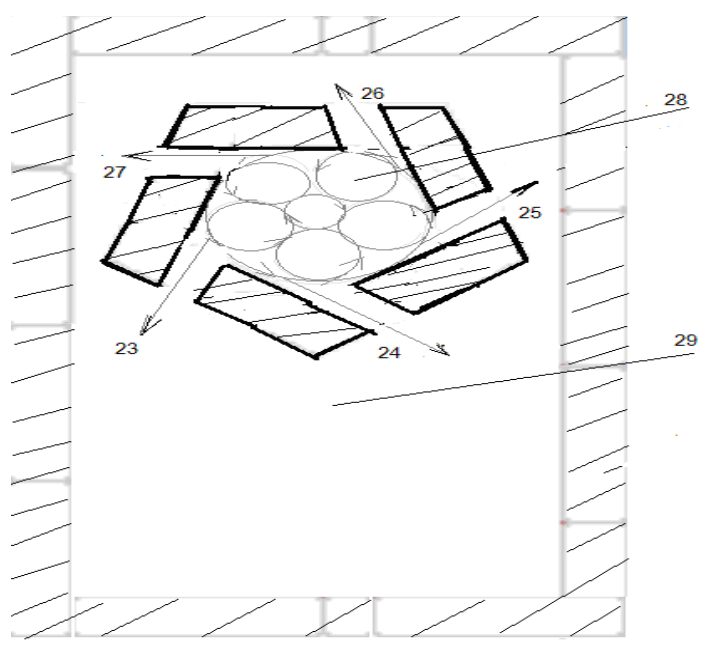

Fig. 14. VM in a house-hold furnace compound - section in plan third (3) unit. The arrows show working mixture motion direction. Five great vortices, united into one macro-motion, decompose in channels $(23,24,25,26,27)$ of an uncurling device (4) and get into convective system for use in heat engineering purposes. Symbols: 23, 24, 25, 26, 27 - channels of uncurling device (4); 28 third (2) unit of plasma-cyclone pentahedron mixer, 29 - convective system, heat exchange zone.

The device works in the following way (see fig.12, 13, 14). In the first, lower (1) unit (see fig.12) through $(7,8,9,10,11)$ channels, oriented along $\mathrm{VM}$ wall in one given direction (clockwise or counter - clockwise), is fed the air. In the middle, second (2) unit (see fig.13) through $(15,16,17,8,9)$ channels, oriented along VM wall in the 
ISSN: 2446-2918 DOI: 10.21058/gjecs.2019.42001

same direction (clockwise or counter-clockwise), carbon containing gases mixture is fed. The way of feed through $(7,8,9,10,11$ and $16,17,18,19)$ channels, made in conformity with given description, causes assured vortex cycloid moving of hot gases along the mixer wall in a direction pre-set by these channels. The mixture is thoroughly mixed in vortex motion and is involved into burning chemical reaction. Gases not having reacted, cold and ballast ones are rejected to the mixer center, as having less kinetic energy, they get rotation direction opposite to the external macrorotation and further are fed to the third (3) unit and through the diaphragm (5) in the tube (6). Hot gases in the third (3) unit (see fig.14) are picked by the uncurling device (4) through $(23,24,25,26,27)$ channels into convection system (29) for using in heat engineering purposes and dropped into the tube (6) after utilization.

\section{Economic Profit}

Economic profit of VM use in carbon containing fuel combustion plants can be estimated in the following way. Considering the effect of mixture thorough mixing, we think that burning reaction is maintained by a minimal, i.e. stacheometric quantity of air oxygen. Let us estimate for certainty the economic profit of VM use in an ordinary average statistic fire-wood furnace, designed for an average statistic room of $40 \mathrm{~m} 2$ heat losses with heat losses of $50 \mathrm{~W} / \mathrm{m} 2$, i.e. for a furnace of $2 \mathrm{KW}$ capacity; in this case we assume, that $1 \mathrm{~kg}$ of fire-wood releases in average by low rate -2.7 $\mathrm{KW}^{*} \mathrm{~h}$ of chemical energy, and excess air ratio for existing heat engineering devices, working on fire-wood, is equal to 1.7 in average, what corresponds to air consumption of $10.2 \mathrm{~m} 3$ for $1 \mathrm{~kg}$ of fire-wood. Then we get, that a day fire-wood consumption for this room should make the value $\mathrm{M}$, which will be defined in the following way: $\mathrm{M}=2$ $\mathrm{KW}^{*} 24 \mathrm{~h} * 1 \mathrm{~kg} / 2.7 \mathrm{KW} * \mathrm{~h}=17.7 \mathrm{~kg}$ of fire-wood. The air day consumption from $17.7 \mathrm{~kg}$ fire-wood combustion in an average static furnace will make the value V1, defined by the formula: $\mathrm{V} 1=17.7 \mathrm{~kg} * 10.2 \mathrm{~m} 3 / 1 \mathrm{~kg}=180 \mathrm{~m} 3$ (rounded). With VM use, the air day consumption $\mathrm{V} 2$ for a furnace of analogous capacity will be defined as follows: $\mathrm{V} 2=17.7 \mathrm{~kg} * 6 \mathrm{~m} 3 / 1 \mathrm{~kg}=106 \mathrm{~m} 3$ (rounded). It means, that VM use in a fire-wood furnace of $2 \mathrm{KW}$ will provide a chemical burning process with lesser air volume for $74 \mathrm{~m} 3$, then existing average stat istic firewood furnaces of the same capacity. Any air passing through the furnace, is heated, and on the tube section it has got the temperature of $150 \mathrm{C}$ in average (for estimation). If to suppose the air average temperature at the plant inlet in the heating season-10C, we will get the following value for the plant capacity loss $\mathrm{Q}$ from heat discharge by ballast air: $\mathrm{Q}=\mathrm{cm}(\mathrm{T} 1-\mathrm{T} 2)=\mathrm{cVp}(\mathrm{T} 1-\mathrm{T} 2)$, where $\mathrm{c}=1.005 \mathrm{KDJ} / \mathrm{kg}^{*} \mathrm{~K}$ is air specific heat, $\mathrm{m}=\mathrm{Vp}$ - excess air mass, $\mathrm{V}=74 \mathrm{~m} 3$ - excess ballast air volume, $\mathrm{p}$ $=1.2 \mathrm{~kg} / \mathrm{m} 3$ - air average density for normal conditions, T1- temperature on the tube section, T2 - air temperature at the plant inlet. Substituting values into the formula for capacity loss Q, we will get: $\mathrm{Q}=1.005 \mathrm{KDJ} / \mathrm{kg} * \mathrm{~K} * 74 \mathrm{~m} 3 * 1.2 \mathrm{~kg} / \mathrm{m} 3 *(423 \mathrm{~K}$ $263 \mathrm{~K})=14279 \mathrm{KDJ}$, what corresponds to $4 \mathrm{KW}^{*}$, i.e. to combustion of nearly $1.5 \mathrm{~kg}$ fire-wood or $8.5 \%$ of fire-wood total day consumption in a furnace of such capacity. It means that approximate economic effect of VM use is $8.5 \%$ of fuel economy. This estimation of VM use economic profit can essentially differ from real one, that is 
ISSN: 2446-2918 DOI: 10.21058/gjecs.2019.42001

towards greater values, since actual gases temperatures on the tube section can be higher, than 150C. Besides, in a chimney stack with VM is admitted an average temperature on the outer section even less than $100 \mathrm{C}$, as it will not lead to a condensate forming, actually, by the tube wall cycloid has an increased temperature; and then the economic effect of the device use is even higher, than $8.5 \%$. This estimation doesn't consider either, that VM prolongs the working gases interaction way for a value $\mathrm{L}$, defined by the approximate formula $\mathrm{L}=2 * \mathrm{pi} * \mathrm{R} * \mathrm{Z}$; where $\mathrm{pi}=3.149265$ is pi number, $\mathrm{R}-\mathrm{VM}$ radius, $\mathrm{Z}$ - the number of rotations, which the working mixture will make along the mixer axis; that's why the working mixture is held in the mixer zone longer for a value $t$, defined by the formula $t=L / v$ $=2 * \mathrm{pi}^{*} \mathrm{R} * \mathrm{R} * \mathrm{Z} / \mathrm{w}$, where $\mathrm{v}$ is gases average linear speed, $\mathrm{w}$-gases average angular speed. The time $\mathrm{t}$ - is interaction in the mixer additional time, during which carbon containing gases with chemical interaction higher temperature are involved in burning, capacity and combustion efficiency are increased, noxious substances blow-out is reduced. Also, it is not considered that the chemical reaction will take place on a much larger scale. Taking into consideration all that is said above, one can surely state, that $8.5 \%$ of economy is only a very modest bottom value. VM practical use in house-hold furnaces, beginning from 2011, has shown, that fuel economy comes out to be much higher than this given bottom value, it approaches $50 \%$. In 2011 our article on VM has been published - http://stoveweb.com/?keyword=smesitel

\section{References}

1. Govorov V.I., Plotnikov V.M., Karatay E.V.-- Theoretical foundations of burning and explosion.- Temirtau: KGIU, 2007 (7.4. Burning acceleration factors).

2. Fujita T. A detailed analysis of the Fargo tornadoes of June, 1957, Res. Pap., No 42 Weather Bur. Unit. Stat., 1960.

3. Merkulov A. P. Vortex effect and its using in technics. - Samaa: Optima, 1997.

4. Nevolin V.G. The experience of sound effect using in Perm region oil production practice.- Perm, 2008.

5. Semenov N.N. Chain reactions. L.: ONTI, 1934; II edition. M.: Science, 1986.

6. Schauberger V. Water energy. - Yausa: Eksmo, 2007.

7. Styrikovitch M.A. Solid fuel combustion problems in big energetics. -M.: Science, 1989.

8. Suslov A.D., Ivanov S.V., Murashkin A. V., Chizhikov Y.V. Vortex aggregates. - M.: Machine building, 1985.

9. Wobus H. B. Tornado from cumulo-nimbus. Bull.Amer. Met. Soc. v.21, No 9, 1940, pp.367-368.

10. Zeldovitch Y.B., Barenblatt G.I., Librovitch V. B., Mahviladze G.M. Mathematical theory of burning and explosion — M.: Science, 1980. 